\title{
QUALIDADE SANITÁRIA DA CARNE DE SOL COMERCIALIZADA EM AÇOUGUES E SUPERMERCADOS DE JOÃO PESSOA - PB
}

\author{
ELIZABETE LOURENÇO DA COSTA * \\ JOÃO ANDRADE SILVA **
}

\begin{abstract}
Cortes de carne bovina submetidos à salga branda (carne de sol) foram analisados sob o ponto de vista físico-químico e microbiológico. Verificou-se sua qualidade sanitária pela contagem total de bactérias aeróbias, Staphylococcus aureus e pesquisa do número mais provável (NMP) de coliformes totais e fecais. Simultaneamente foram determinados o teor de cloreto e a atividade de água $\left(\mathrm{a}_{\mathrm{w}}\right)$. O resultado das análises físico-químicas revelaram que o teor de sal deste produto variou entre 3,73 e $9,79 \%$. Nestas concentrações de sal, a $a_{w}$ variou de 0,898 a 0,967, valores bastante apropriados para o desenvolvimento de grande número de microrganismos, tanto patogênicos como deteriorantes. Nas análises microbiológicas verificou-se que a contagem total de microrganismos aeróbios, em quase todas as amostras encontrou-se acima de cinco ciclos logarítmicos. A presença de Staphylococcus aureus em $50 \%$ das amostras, também foi superior a 5 log UFC/ $/ \mathrm{cm}^{2}$ e o número mais provável de coliformes fecais acima de $10^{3} \mathrm{NMP} / \mathrm{cm}^{2}$ em $60 \%$ das amostras analisadas. Estes resultados sugerem que a carne de sol comercializada em João Pessoa pode estar sendo produzida a partir de matériasprimas de qualidade microbiológica inadequada ou o produto está sendo contaminado durante uma ou mais etapas de produção, transporte, armazenamento ou comercialização.
\end{abstract}

\section{INTRODUÇÃO}

A carne de sol é elaborada pela ação combinada de salga e desidratação parcial da carne bovina (15). Em tempos remotos, antes da popularização da conservação de alimentos pelo frio, altas concentrações de sal e secagem ao sol produziam carne salgada e seca, e conseqüentemente,

* Aluna do Curso de Pós-Graduação em Engenharia de Alimentos, Faculdade de Engenharia de Alimentos (FEA), UNICAMP, Campinas, SP.

** Professor, Dep. de Nutrição, Universidade Federal da Paraíba (UFPB), João Pessoa, PB (e-mail: andradebr@yahoo.com.br). 
com vida-de-prateleira relativamente longa, mesmo quando armazenada em temperatura ambiente, se comparada à carne fresca.

O processo de salga altera a pressão osmótica da carne, que remove água dos tecidos, o que provoca redução da atividade de água, inibindo o desenvolvimento microbiano, bem como, a velocidade de reações indesejáveis no produto final. Portanto, mesmo quando conservada sem refrigeração a carne salgada apresenta vida-de-prateleira superior à carne fresca (12). Com o advento da refrigeração, este processo de conservação perdeu muito de sua importância, mas, acostumados ao sabor característico do produto, os povos de algumas regiões do Brasil, principalmente os nordestinos, continuaram produzindo a carne de sol, utilizando menores quantidades de sal e muitas vezes sem exposição ao sol. Cada estado desenvolveu tecnologia própria, resultando em produtos com características diferentes, quanto ao aspecto, sabor, cor, teor de sal e vida-de-prateleira. Este novo produto, muitas vezes elaborado em condições sanitárias inadequadas, tanto pode conter microrganismos patogênicos capazes de colocar em risco a saúde do consumidor, como microrganismos deterioradores capazes de alterar o produto em períodos de tempo muito curtos. Sua conservação depende diretamente das condições gerais de processamento e dos cuidados com embalagem, armazenamento e transporte.

Vários autores têm sugerido modificações na elaboração da carne de sol. NÓBREGA (10) propôs a utilização de doses reduzidas de nitrito ou nitrato de sódio ou sorbato de potássio. Estas alternativas retardam substancialmente a deterioração do produto, tanto quando armazenado a temperatura ambiente, como quando mantido sob refrigeração, entretanto o uso de aditivos químicos pode descaracterizar o produto. Para elaborar produto cárneo de boa qualidade, FRAZIER \& WESTHOFF (5) recomendam a utilização de carne com boa qualidade microbiológica, pois se houver crescimento de importante número de microrganismos, o produto resultante apresentará sabor e odor desagradáveis. As carnes preparadas dentro dos padrões higiênicos-sanitários contém número de microrganismos patogênicos muito reduzido, sendo possível encontrar representantes dos gêneros Listeria, Clostridium, Salmonella, Campylobacter e Staphylococcus (7).

Considerando a importância dos microrganismos na alteração da carne é necessário que durante sua manipulação, armazenamento e conservação, o crescimento microbiano seja retardado ou quando possível inibido. Dos diversos procedimentos empregados para atingir este objetivo, a refrigeração constitui o método de conservação mais utilizado, aumentando a vida-de-prateleira da carne, sem contudo, provocar modificações no produto $(5,9)$. 
Não obstante a carne de sol revestir-se de importância fundamental na alimentação da população nordestina, a literatura pertinente revela poucos resultados de pesquisas sobre a carne de sol.

O presente trabalho foi realizado com o objetivo de detectar e quantificar os microrganismos que possam servir de indicadores de qualidade para a carne de sol, além de suas propriedades intrínsecas, como teor de cloretos e atividade de água, que são fatores essenciais para o desenvolvimento dos microrganismos.

\section{MATERIAL E MÉTODOS}

\subsection{MATERIAL}

As amostras foram coletadas em diversos estabelecimentos comerciais, licenciados oficialmente para a comercialização de alimentos. Os cortes foram codificados, ignorando-se o local de sua coleta, acondicionados em recipientes adequados, transportados até o Laboratório de Microbiologia de Alimentos, do Departamento de Nutrição CCS/UFPB e imediatamente analisados microbiológica e físico-quimicamente.

\subsection{MÉTODOS}

\subsubsection{Análises Microbiológicas}

Para as análises microbiológicas a amostragem foi realizada em área de $25 \mathrm{~cm}^{2}$, da superfície da carne, segundo recomendações de DELAZARI et al. (3) e de LEE \& FUNG (8), utilizando-se zaragatoa e molde metálico estéreis. A amostra foi homogeneizada em água peptonada e convenientemente diluída para a realização das análises.

\section{Contagem total de bactérias aeróbias mesófilas}

Efetuadas as diluições necessárias, as amostras foram semeadas com $1,0 \mathrm{~mL}$ de cada diluição, em "Plate Count Agar" (PCA) e incubadas a $37^{\circ} \mathrm{C}$ por 48 horas (14).

\section{Pesquisa de bactérias coliformes}

Semeou-se 1,0 $\mathrm{mL}$ de cada diluição em uma série de três tubos contendo caldo lauril-sulfato triptose, os quais foram incubados em estufa a $35{ }^{\circ} \mathrm{C}$ por 48 horas. Os tubos que apresentaram formação de gás, no interior do tubo de Duhran foram considerados positivos. A partir dos tubos positivos, com o auxílio de uma alça de platina, alíquotas foram repicadas para tubos contendo caldo verde bile brilhante e incubadas em estufa a $35{ }^{\circ} \mathrm{C}$ por 48 
horas para verificar a presença de coliformes totais. Os tubos considerados positivos no teste presuntivo foram repicados para tubos contendo caldo $\mathrm{EC}$, os quais foram incubados em banho-maria a $44,5 \pm 0,2^{\circ} \mathrm{C}$ por 24 horas para verificar a presença de coliformes fecais (14).

\section{Pesquisa de Staphylococcus aureus}

Utilizou-se a técnica de semeadura em superfície, semeando 0,2 $\mathrm{mL}$ da suspensão bacteriana, em placas contendo o ágar Vogel Johnson, espalhada com o auxílio de alça de Drigalsky, sendo as placas incubadas invertidas em estufa a $36^{\circ} \mathrm{C}$, por 48 horas (14).

\subsubsection{Análises físico-químicas}

\section{Teor de cloretos}

Adicionou-se ferro cianeto e acetato de zinco à 1,0 g de amostra em banho-maria. Após filtração realizou-se a titulação com nitrato de prata $0,1 \mathrm{~N}$ até o início de formação de cor tijolo, segundo método oficial da AOAC (1).

\section{Atividade de água $\left(A_{w}\right)$}

$A A_{w}$ foi determinada por método direto, utilizando-se higrômetro, da marca Aqua Test, de acordo com o método exposto por NOREÑA et al. (11).

\section{RESULTADOS E DISCUSSÃO}

A Tabela 1 indica os resultados das análises físico-químicas da carne de sol. Pode-se observar que a atividade de água $\left(A_{w}\right)$ de todas as amostras é relativamente alta, variando de 0,898 a 0,967. A carne de sol produzida na atualidade, no Nordeste do Brasil, muitas vezes não é exposta ao sol para secagem, e quando isto acontece, a exposição é feita no início da manhã ou no final da tarde, por período relativamente curto (15), insuficiente para provocar a desidratação do produto. Segundo LEITÃO (9) $a_{w}$ superior a 0,83 permite o crescimento de grande quantidade de microrganismo, tanto deterioradores como os patogênicos causadores de infecções alimentares (Salmonella sp., Clostridium perfringens e Vibrio parahaemolyticus) e os causadores de intoxicações (Bacillus cereus, Staphylococcus aureus e Clostridium botulinum).

O teor de sal da carne de sol, produzida com quantidades de sal adequada ao paladar humano, conforme metodologia descrita por VASCONCELOS (15) não pode ser utilizado para inibir o crescimento de microrganismos 


\section{TABELA 1 - RESULTADOS DAS ANÁLISES FÍSICO-QUÍMICAS REALIZADAS EM CARNE DE SOL COMERCIALIZADA EM JOÃO PESSOA}

\begin{tabular}{ccc}
\hline $\mathrm{N}^{\circ}$ da Amostra & \\
\hline 1 & Atividade de Água & Cloreto de Sódio (\%) \\
2 & 0,959 & 6,33 \\
3 & 0,955 & 5,18 \\
4 & 0,953 & 7,96 \\
5 & 0,955 & 5,08 \\
6 & 0,949 & 6,22 \\
7 & 0,945 & 5,22 \\
8 & 0,967 & 4,78 \\
9 & 0,955 & 3,73 \\
10 & 0,898 & 9,79 \\
\hline
\end{tabular}

${ }^{1}$ Média de três repetições.

neste produto. A maioria dos microrganismos, tanto os patogênicos como os deterioradores são capazes de se desenvolver em substratos com teores de sal inferiores a $10 \%$, principalmente quando este substrato contem $\mathrm{a}_{\mathrm{w}}$ adequada para seu desenvolvimento (13). O teor de cloreto de sódio encontrado nas amostras analisadas é bastante variado, de 3,73 a 9,79 . Como pode ser verificado na Tabela 1 , os valores de $a_{w}$, variaram conforme o teor de cloreto de sódio.

Os resultados obtidos nas análises microbiológicas da carne de sol são apresentados na Tabela 2. A Portaria $n^{\circ} 451 / 97$ do Ministério da Saúde (2) não estabelece parâmetros para a quantidade máxima de microrganismos aeróbios em carnes, porém FUNG et al. (6) consideram que, contagens bacterianas inferiores a $2 \log \mathrm{UFC} / \mathrm{cm}^{2}$ indicam baixa contaminação, contagens entre 3 e $4 \log \mathrm{UFC} / \mathrm{cm}^{2}$ revelam contaminação intermediária e contagens entre 5 e $6 \mathrm{log} \mathrm{UFC} / \mathrm{cm}^{2}$ representam alta contaminação. De acordo com esta definição, a carne analisada no presente trabalho pode ser classificada como portadora de contaminação microbiológica alta, por apresentarem contagem total de bactérias mesófilas e Staphylococcus aureus superiores a cinco ciclos logarítmicos. 


\section{TABELA 2 - RESULTADOS DAS ANÁLISES MICROBIOLÓGICAS REALIZADAS EM CARNE DE SOL COMERCIALIZADA EM JOÃO PESSOA}

\begin{tabular}{|c|c|c|c|c|}
\hline $\mathrm{N}^{\circ}$ da Amostra ${ }^{1}$ & $\begin{array}{l}\text { Bactérias } \\
\text { Mesófilas }^{2}\end{array}$ & $\begin{array}{c}\text { Coliformes } \\
\text { Totais }^{3}\end{array}$ & $\begin{array}{c}\text { Coliformes } \\
\text { Fecais }^{3}\end{array}$ & $\begin{array}{c}\text { Staphylococcus } \\
\text { aureus }^{2}\end{array}$ \\
\hline 1 & 5,7 & $>2400$ & 1100 & 4,9 \\
\hline 2 & 6,9 & 1100 & 1100 & 6,2 \\
\hline 3 & 5,1 & 240 & 93 & 2,6 \\
\hline 4 & 6,0 & 1100 & 1100 & 3,5 \\
\hline 5 & 3,2 & 1100 & 240 & 2,4 \\
\hline 6 & 3,9 & 1100 & 1100 & 3,2 \\
\hline 7 & 6,5 & 2400 & 1100 & 6,2 \\
\hline 8 & 6,1 & 2400 & 1100 & 5,9 \\
\hline 9 & 7,4 & 93 & 43 & 6,4 \\
\hline 10 & 6,3 & 240 & 4 & 5,5 \\
\hline
\end{tabular}

${ }^{1}$ Média de três repetições.

${ }^{2}$ Unidade formadora de Colônia (log UFC/ $/ \mathrm{cm}^{2}$ ).

${ }^{3}$ Número Mais Provável de Coliformes Fecais $\left(\mathrm{NMP} / \mathrm{cm}^{2}\right)$.

Na maioria das amostras analisadas detectou-se número mais provável de coliformes fecais bastante elevado, porém a presença deste grupo de microrganismos em carnes também não é regulamentada pela legislação brasileira. De acordo com FRAZIER \& WESTHOFF (5) sua presença em carnes sugere que pode ter ocorrido falha na higiene, durante uma ou mais etapas do processo produtivo. Assim, a carne de sol tanto pode ter sido elaborada com matéria-prima contaminada, por material fecal do próprio animal, durante 0 abate, como pode ter sido contaminada pelos manipuladores, durante sua produção, transporte, armazenamento ou até mesmo nos locais de comercialização. A carne é exposta, ao público, sem nenhum tipo de embalagem, podendo ser tocada por qualquer pessoa que desejar. Este fato também pode ser responsável pela presença de Staphylococcus aureus em todas as amostras analisadas, já que estes microrganismos encontram-se naturalmente na pele e nas fossas nasais dos seres humanos. A presença de coliformes fecais em alimentos manipulados pode indicar a ocorrência de contaminação fecal após o processamento, evidenciando práticas de manufatura em desacordo com os padrões normais de processamento de alimentos. A presença destes microrganismos pode indicar ainda que o alimento contém microrganismos patogênicos de origem intestinal, como Salmonella (9).

Observa-se pela Tabela 2 que as amostras portadoras das maiores concentrações de cloreto de sódio apresentaram os menores valores na pesquisa do número mais provável de coliformes fecais. No entanto, a contagem total de bactérias mesófilas e de Staphylococcus aureus não variou conforme a concentração de cloreto de sódio. 


\title{
4 CONCLUSÃO
}

De acordo com os resultados das análise realizadas neste trabalho podese concluir que a quantidade de sal utilizada atualmente na produção da carne de sol é insuficiente para reduzir a atividade de água $\left(A_{w}\right)$ deste produto, e conseqüentemente não exerce ação inibidora significativa no desenvolvimento da maioria dos microrganismos presentes na carne.

O elevado número de microrganismos aeróbios, de Staphylococcus aureus e coliformes fecais na maioria das amostras analisadas sugere falhas em uma ou mais etapas do processo produtivo da carne de sol, seja na obtenção da matéria-prima ou na elaboração do produto. Esta carne foi considerada altamente contaminada, podendo provocar distúrbios gastrointestinais nos consumidores.

\begin{abstract}
Bovine meat soft salted, known as "carne-de-sol", a typical northeastern Brazilian product, had its physicochemical (chloride and water activity) and microbiological (aerobic count plate, Staphylococcus aureus and coliforms) characteristics analysed in order to evaluate the sanitary conditions. The analyses revealed that the salt content varied from 3.73 to $9.79 \%$ whereas the water activity ranged within 0.898 and 0.959 . Such conditions allow the growth of pathogenic microorganisms and consequent bacteria spoilage. The microbiological analyses showed that the presence of mesophilic bacteria in all samples was reaching values above 5 logarithmic cycles. The presence of Staphylococcus aureus was observed in $50 \%$ of the samples, being noted values higher than $10^{5} \mathrm{CFU} / \mathrm{cm}^{2}$; the most probable number for fecal coliforms reached levels above $10^{3} \mathrm{MPN} / \mathrm{cm}^{2}$ in $60 \%$ of the meat sampled. It may be inferred that this meat product marketed in the city of João Pessoa, Brazil, has been either produced with raw meat of inadequate sanitary conditions or contaminated during the process of production, transportation, storage and commercialization
\end{abstract}

\section{REFERÊNCIAS BIBLIOGRÁFICAS}

1 ASSOCIATION OF OFFICIAL ANALYTICAL CHEMISTS. Official methods of analysis. 14.ed. Washington, 1984.

2 BRASIL. Ministério da Agricultura. Portaria n. 451 de 19 de setembro de 1997. Dispõe sobre as normas e padrões de controle microbiológico para alimentos. Diário Oficial [da República Federativa do Brasil], Brasília, 19 set. 1997.

3 DELAZARY, I., GERALDINI, A. M., LEITÃO, M. F. F. , CORTE, O. O. Incidência de bactérias esporogênicas anaeróbias em carne bovina. B. ITAL, v. 17, n. 4, p. 441-450, 1980.

4 ELLIOT, H. P. Predictive microbiology and HACCP. J. Food Protection, Suplement, p. 48-53, 1996. 

alimentos. Zaragoza : Acribia, 1993. $681 \mathrm{p}$.

6 FUNG, D. Y. C., KASTNER, C. L., HUNT, M. C., DIKEMAN, M. E., KROPF, D. Mesophilic and psychrotrophic bacteria population on hot-boned and conventionally processed beef. J. Food Prot., v. 43, n. 7, p. 547-550, 1980.

7 GARCIA, T., MATRÍ, R., SANZ, B., HERNANDEZ, P. E. Revision: extensión de la vida útil de la carne fresca I: envasado en atmosferas modificadas y utilización de bactérias lácticas y bactericinas. R. Esp. Cienc. Tecnol. Aliment., v. 35, n. 1, p. 118, 1995.

8 LEE, J. Y., FUNG, D. Y. C. Methods for sampling meat surfaces. J. Environm. Health, v. 48, n. 4, p. 200-205, 1986.

9 LEITÃO, M. F. F. Microbiologia de alimentos. In: ROITMAN, I., TRAVASSOS, L. R., AZEVEDO, J. R. Tratado de Microbiologia. São Paulo : Manole, 1988. v. 1, p. 3-81.

10 NÓBREGA, D. M. Contribuição ao estudo da carne de sol visando melhorar sua conservação. Campinas, 1982. 81 p. Tese (Mestrado em Tecnologia de Alimentos), Faculdade de Engenharia de Alimentos - Universidade Estadual de Campinas/UNICAMP.

11 NOREÑA, C. Z., HUBINGER, M. D., MENEGALLI, F. C. Técnicas básicas de determinação de atividade de água: uma revisão. $B$. SBCTA, v. 30, n. 1, p. 91-96, 1986. v. 5, p. $11-30,1980$.

SILLIKER, J. H. Ecologia microbiana de los alimentos. Zaragoza : Acribia, 1980. v. 2, 656 p.

VANDERZANT, C., SPLITTSTOOSSER, R. D. F. Compendium of methods for the microbiological examination of foods. 15.ed. Washington, DC. : APHA, 1992. 1219 p. n. 5, p. 15-20, 1986. 